\title{
Cost-effectiveness of six strategies for Helicobacter pylori diagnosis and management in uninvestigated dyspepsia assuming a high resource intensity practice pattern
}

\author{
Kyland P Holmes', John C Fang ${ }^{2}$, Brian R Jackson ${ }^{3 *}$
}

\begin{abstract}
Background: Initial assessment of dyspepsia often includes noninvasive testing for Helicobacter pylori infection. Commercially available tests vary widely in cost and accuracy. Although there is extensive literature on the costeffectiveness of $\mathrm{H}$. pylori treatment, there is little information comparing the cost-effectiveness of various currently used, noninvasive testing strategies.
\end{abstract}

Methods: A Markov simulation was used to calculate cost per symptom-free year and cost per correct diagnosis. Uncertainty in outcomes was estimated using probabilistic sensitivity analysis.

Results: Under the baseline assumptions, cost per symptom-free year was $\$ 122$ for empiric proton pump inhibitor (PPI) trial, and costs for the noninvasive test strategies ranged from $\$ 123$ (stool antigen) to $\$ 129$ (lgG/lgA combined serology). Confidence intervals had significant overlap.

Conclusions: Under our assumptions for how testing for $\mathrm{H}$. pylori infection is employed in United States medical practice, the available noninvasive tests all have similar cost-effectiveness between one another as well as with empiric PPI trial.

\section{Background}

Many diagnostic scenarios require a physician to choose from among a set of related diagnostic tests. For Helicobacter pylori infection in the setting of dyspepsia, diagnostic options include serologic tests, a stool antigen test, a urea breath test, and invasive methods, such as endoscopy with biopsy. These options vary with regard to cost, convenience, and accuracy. The decision about which test to order may ultimately be a significant driver of downstream economic costs and quality-of-care outcomes. The American Gastroenterological Association (AGA) in 2005 recommended that to diagnose Helicobacter pylori infection in patients with dyspepsia, physicians should use either the stool antigen test or the urea breath test. [1,2] Serologic tests were specifically not recommended due to

\footnotetext{
* Correspondence: brian.jackson@aruplab.com

${ }^{3}$ Department of Pathology, University of Utah, Salt Lake City, Utah, USA

ARUP Laboratories, Salt Lake City, Utah, USA

Full list of author information is available at the end of the article
}

inferior sensitivity and specificity. The American College of Gastroenterology (ACG) issued a similar guideline in 2007 that discussed the tradeoffs among available tests but left the test choice up to physician judgment. [3] The testing volume for $H$. pylori at a national reference laboratory (ARUP Laboratories, Salt Lake City, Utah) suggests that serology is more widely used than would be expected under the AGA-recommended approach. ARUP received approximately four times as many orders for $\mathrm{H}$. pylori serology between April 1, 2007, and March 31, 2008, than for either stool or breath tests. For this reason, serology is included in the current analysis.

A number of published articles address the cost-effectiveness of $H$. pylori management, but most of these primarily compare treatment options after a patient has already been diagnosed with $H$. pylori. [4-25] Others compare early endoscopy to empiric therapy and/or noninvasive testing. [26-32] Still others compare the effectiveness within a small subset of tests of diagnosing
C Biomed Central

C 2010 Holmes et al; licensee BioMed Central Ltd. This is an Open Access article distributed under the terms of the Creative Commons Attribution License (http://creativecommons.org/licenses/by/2.0), which permits unrestricted use, distribution, and reproduction in any medium, provided the original work is properly cited. 
H. pylori infection or of determining the efficacy of treatment. [27-30,33-43] At least one article has assessed cost-effectiveness of multiple noninvasive tests before and after diagnosis. [44] Given that "test and treat" using noninvasive tests is a common approach to uninvestigated dyspepsia in the United States, the specific noninvasive test strategy becomes a key decision point. We therefore compared the cost-effectiveness of some of the most common noninvasive testing strategies for H. pylori along with empiric proton pump inhibitor (PPI) trial in the management of uninvestigated dyspepsia.

\section{Methods}

This study compared six diagnostic strategies [Table 1] for initial management of patients with dyspepsia. The first step of strategies 1 through 5 was a different noninvasive test, and empiric PPI therapy was included for completeness as a sixth strategy. In order to calculate the impact (both cost and benefit) of the choice of diagnostic test we had to first create a model of the expected care process for these patients. We intentionally did not use an idealized care process, but rather modeled it to reflect typical local practice for managing dyspepsia (Figure 1). We also believe it to be a reasonable representation of a practice patterns for dyspepsia across much of the US.

The primary measure of outcome was the cost (US\$) per symptom-free year. As the length of triple therapy or PPI trial is typically 14 days and this is the event of shortest duration in the model other than initial testing, the Markov cycle was defined as two weeks.

Key assumptions in this model include:

1. All patients enter the model with uninvestigated dyspepsia. There is some probability that the patient has an $H$. pylori infection, peptic ulcer(s), or both.

2. In keeping with AGA and ACG guidelines, the model considers only patients younger than 55 years of

\section{Table 1 Description of strategies modeled}

\begin{tabular}{|c|c|}
\hline Strategy & Description \\
\hline $\lg G / \lg A$ & $\begin{array}{l}\text { Begin with } \mathrm{H} \text {. pylori lgG and IgA tests. If either is } \\
\text { positive, do triple therapy. If both are negative, } \\
\text { do PPI trial. }\end{array}$ \\
\hline $\lg G$ & $\begin{array}{l}\text { Begin with } \mathrm{H} \text {. pylori lgG test. If positive, do triple } \\
\text { therapy. If negative, do PPI trial. }\end{array}$ \\
\hline Stool Antigen & $\begin{array}{l}\text { Begin with } \mathrm{H} \text {. pylori stool antigen test. If positive, } \\
\text { do triple therapy. If negative, do PPI trial. }\end{array}$ \\
\hline $\begin{array}{l}\text { IgG with reflex to } \\
\text { stool Antigen }\end{array}$ & $\begin{array}{l}\text { Begin with IgG test. If positive, confirm with } \\
\text { stool antigen detection. If both tests are positive, } \\
\text { do triple therapy. Otherwise, do PPI trial. }\end{array}$ \\
\hline Breath Test & $\begin{array}{l}\text { Begin with } H \text {. pylori urea breath test. If positive, } \\
\text { do triple therapy. If negative, do PPI trial. }\end{array}$ \\
\hline PPI trial & $\begin{array}{l}\text { Skip noninvasive testing and begin instead with } \\
\text { PPI trial. }\end{array}$ \\
\hline
\end{tabular}

age who lack alarm features, such as bleeding or weight loss. Accordingly, the model does not consider the downstream costs or the medical consequences of gastric cancer, perforated ulcers, and other potentially lifethreatening conditions.

3. Any patient who tests positive for $H$. pylori will be administered a course of standard triple therapy (clarithromycin, amoxicillin, and lansoprazole).

4. If there is no relief of symptoms after initial management, or if symptoms recur, he or she will go on to receive an endoscopy with a biopsy. This assumption was followed not in an attempt to reflect evidence-based practice, but rather in an attempt to reflect a "typical" approach to dyspepsia management.

5. Following endoscopy, if triple therapy or empiric PPI had been initially effective in relieving symptoms of dyspepsia, and if symptoms remained unresolved or recurred, the patient will receive long-term PPI therapy. As above, this assumption was followed in an attempt to reflect typical practice patterns, rather than evidencebased practice per se.

6. Patients remain in the model for the duration of their life.

The scenarios above were modeled by a Markov chain Monte Carlo (MCMC) method of statistical analysis using the TreeAge Pro software package (TreeAge Software, Inc., Williamstown, Massachusetts). A simplified graphical representation of the model is given in Figure 1. Variable inputs for the model are listed in Table 2. The outcomes measured were total cost of diagnosis and treatment in U.S. dollars and the amount of time spent symptom-free. The cost perspective taken was societal.

Probabilities employed in the model were based on published literature where available. Expert opinion was provided by one of the coauthors (JCF). Baseline costs of tests and treatments were based on 2009 national midpoint Medicare reimbursement rates. Second-order probabilistic sensitivity analysis, simulating 250 trials involving 10,000 patients each, was undertaken to measure the extent to which parameter uncertainty might affect the model outcomes. Incremental cost-effectiveness ratios (ICERs) were calculated based on a single simulated cohort of 500,000 patients using empiric PPI trial (i.e., no testing) as the baseline for comparison.

\section{Results}

The cost-effectiveness ratios for the six initial management strategies were similar (Table 3); stool antigen and empiric PPI trial were essentially equivalent, and both strategies were mildly superior to the remaining diagnostic test strategies. Some previously published costeffectiveness analyses have reported results in the form of mean cost per correct diagnosis; to allow easier 


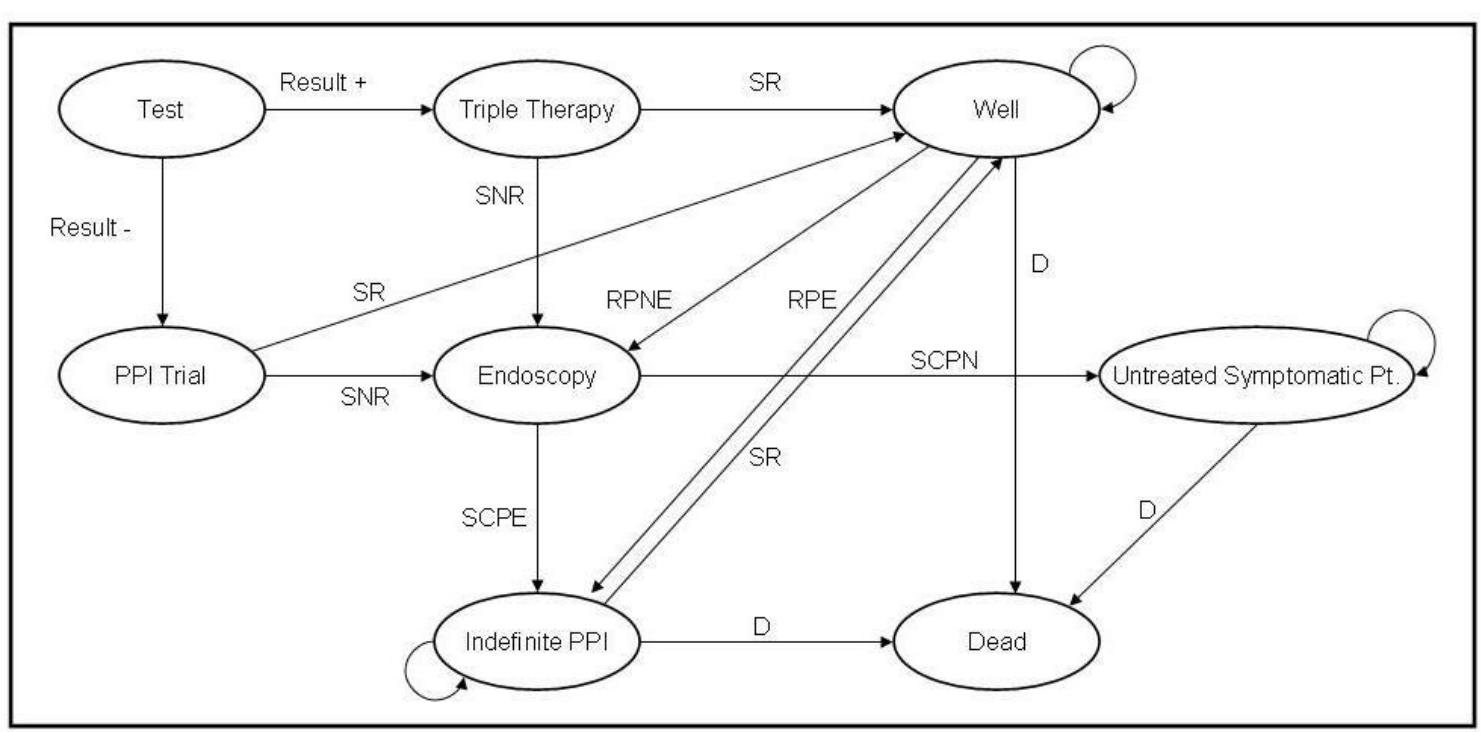

Figure 1 Diagram of $\boldsymbol{H}$. pylori Markov model. SR = Symptoms resolve. SNR = Symptoms do not resolve. RPE = Relapse, PPI initially effective. RPNE $=$ Relapse, PPI not initially effective. $D=$ Death from all causes. SCPE = Symptoms continue, PPI initially effective. SCPN = Symptoms continue, PPI not initially effective.

Table 2 Variables employed in the model

\begin{tabular}{|c|c|c|c|c|}
\hline Variable & Mean & Distribution & 95th percentile * & Reference(s) \\
\hline H. pylori prevalence & 0.23 & Uniform & $0.05-0.4$ & {$[3,44,46]$} \\
\hline Initial ulcer status & 0.10 & Beta & $0.025-.022$ & {$[1,2]$} \\
\hline Cost of IgA serology & $\$ 29$ & Gamma & $12.53-51.34$ & ** \\
\hline Cost of IgG serology & $\$ 29$ & Gamma & $12.53-51.34$ & ** \\
\hline Cost of stool Ag detection & $\$ 21$ & Gamma & $6.20-44.56$ & $* *$ \\
\hline Cost of urease breath test & $\$ 133$ & Gamma & 28.81-316.05 & $* *$ \\
\hline Cost of endoscopy $\mathrm{w} /$ biopsy and pathologist time & $\$ 511$ & Gamma & $156.21-2552.46$ & $* * *$ \\
\hline Cost of eradication therapy & $\$ 355$ & Gamma & 186.55-576.02 & $* * *$ \\
\hline Cost of 2-week PPI therapy & $\$ 40$ & Gamma & $10.92-87.51$ & $* * *$ \\
\hline Breath test sensitivity & 0.95 & Triangular & $0.90-0.98$ & {$[28,34,39,41,44]$} \\
\hline Breath test specificity & 0.96 & Triangular & $0.94-0.99$ & {$[28,34,39,41,44]$} \\
\hline IgA serology sensitivity & 0.85 & Triangular & $0.79-0.90$ & {$[27,29-31,38,41,44,47-51]$} \\
\hline IgA serology specificity & 0.79 & Triangular & $0.65-0.85$ & {$[27,29-31,38,41,44,47-51]$} \\
\hline $\operatorname{lgG}$ serology sensitivity & 0.85 & Triangular & $0.79-0.90$ & {$[27,29-31,38,41,44,47-51]$} \\
\hline $\operatorname{lgG}$ serology specificity & 0.79 & Triangular & $0.65-0.85$ & {$[27,29-31,38,41,44,47-51]$} \\
\hline Stool Ag sensitivity & 0.93 & Triangular & $0.90-0.99$ & {$[27,30,33-35,37,40-44,52-56]$} \\
\hline Stool Ag specificity & 0.92 & Triangular & $0.90-0.99$ & {$[27,30,33-35,37,40-44,52-56]$} \\
\hline Probability of relief of symptoms after two weeks of triple therapy (NUD§) & 0.53 & Beta & $0.28-0.66$ & {$[57]$} \\
\hline Probability of relief of symptoms after two weeks of triple therapy (PUD§§) & 0.49 & Beta & $0.28-0.70$ & [11] \\
\hline Probability of relief of symptoms after two-week PPI trial (NUD) & 0.40 & Beta & $0.40-0.78$ & Expert opinion§§§ \\
\hline Probability of relief of symptoms after two-week PPI trial (PUD) & 0.32 & Beta & $0.47-0.85$ & [11] \\
\hline Probability of relapse at one year after eradication therapy (NUD) & 0.32 & N/A & N/A & [57] \\
\hline Probability of relapse at one year after eradication therapy (PUD) & 0.37 & N/A & N/A & [11] \\
\hline
\end{tabular}

*Calculated by taking 100,000 samples from each distribution.

**These estimates are based on 2009 Medicare reimbursement rates, where the mean is the 2009 midpoint national reimbursement rate as published in the 2009 Clinical Diagnostic Laboratory Fee Schedule, which is available at http://www.cms.hhs.gov/ClinicalLabFeeSched/.

***These figures are based on Medicare reimbursement rates, which are current for 2009 CPT codes and are available from the American Medical Association. $\S$ Non-ulcer dyspepsia.

$\S \S$ Peptic ulcer disease.

§§§John C. Fang, MD, Associate Professor of Gastroenterology, University of Utah, Salt Lake City, Utah 
Table 3 Cost-Effectiveness ratios for each strategy modeled

\begin{tabular}{ll}
\hline Strategy & $\begin{array}{l}\text { Cost per symptom free } \\
\text { year }\left(\mathbf{9 5 \%} \mathrm{Cl}^{*}\right)\end{array}$ \\
\hline Empiric PPI Trial & $122.13(120.00-124.88)$ \\
Stool Ag & $123.23(120.68-125.58)$ \\
lgG serology & $125.76(123.18-128.27)$ \\
lgG serology w/reflex to Stool Ag & $126.17(123.43-128.08)$ \\
Breath test & $128.31(125.69-130.72)$ \\
lgG/lgA binary serology & $129.04(126.43-131.48)$ \\
\hline
\end{tabular}

Numerical values are in \$US per symptom-free year.

comparison with these we provide our results according to this measure in Table 4. None of these results were sensitive to changes in prevalence of $H$. pylori ( $5 \%$ to $40 \%)$.

\section{Discussion}

Assuming that this model and its assumptions reasonably reflect U.S. clinical practice, it appears that the initial choice of noninvasive testing strategy does not have a significant influence on the overall cost-effectiveness of care for patients presenting with previously uninvestigated dyspepsia. This finding holds even when the prevalence of $H$. pylori infection is varied over a wide range ( $5 \%$ to $40 \%$ ).

These findings may seem surprising; it seems intuitive that more accurate testing should lead to improved outcomes and lower overall health spending, provided that the cost of the test itself is reasonable. The key, though, is the set of baseline assumptions about how the tests are used in U.S. clinical practice. In particular, we assumed that in the absence of symptomatic relief, physicians would move fairly quickly to definitive diagnosis (endoscopy with biopsy), thus reducing or even negating the impact of the original noninvasive test (or lack thereof). To use a more extreme illustration, a consequence of our underlying model is that the diagnostic test could be replaced with a random number generator without significantly impacting cost-effectiveness. In settings where endoscopy is less widely employed, the decision about which noninvasive test to order for a patient

Table 4 Cost per correct diagnosis for each strategy modeled

\begin{tabular}{ll}
\hline Testing Strategy & $\begin{array}{l}\text { Average Cost per Correct } \\
\text { Diagnosis }\end{array}$ \\
\hline Stool Ag & $\$ 2767.85$ \\
Breath test & $\$ 2825.24$ \\
lgG Serology & $\$ 3371.91$ \\
lgG serology w/reflex to Stool & $\$ 3373.39$ \\
$\mathrm{Ag}$ & \\
lgG/lgA binary serology & $\$ 4061.91$ \\
\hline
\end{tabular}

would likely have a larger economic and clinical impact, depending on the test chosen.

Vakil et al. estimated the cost-effectiveness of a similar set of noninvasive testing strategies in a 2000 paper [44]. In their model, cost per correct diagnosis using the antibody and stool tests ranged from $\$ 90$ to $\$ 127$. The antibody tests incurred the lowest cost per correct diagnosis at all levels of prevalence that they modeled $(30 \%, 60 \%$, and $90 \%$ ). The stool test was more expensive at low and intermediate prevalence, but with much higher diagnostic accuracy ( 93\%). A key distinction of our model is that we used cost per symptom-free year rather than cost per correct diagnosis as our primary measure, although we did include the latter in our results for comparison. This distinction is significant. First, the clinical goal is typically relief of symptoms rather than diagnosis per se. A patient is unlikely to undergo followup when symptoms have been alleviated, as in the empiric PPI trial or a PPI trial after eradication treatment. The impact of the diagnosis can only be truly assessed in the context of the resulting clinical actions. Therefore, the cost at diagnosis does not reflect the total cost of care. For example, a patient can have an incorrect noninvasive test result, but if the patient still achieves long-term relief of symptoms without incurring too much expense, then from that patient's

perspective, no great harm has been done. We thus believe that cost per symptom-free year is a more appropriate cost-effectiveness measure than cost per correct diagnosis. In a larger sense, our study illustrates some of the challenges in assessing cost-effectiveness of diagnostic tests, as well as the importance of doing so. Because testing is an upstream process, the clinical and economic impacts of diagnostic tests are expressed primarily in the downstream clinical actions. The result from a $\$ 10$ test, for example, might in some cases make the difference between whether to provide a $\$ 10,000$ course of chemotherapy or a surgical procedure. Or, in a different scenario, that same $\$ 10$ test might simply be a waste of $\$ 10$, if the same clinical actions took place regardless of the test result. Superior sensitivity and/or specificity does not guarantee better patient outcomes once the test is placed in the larger context of patient management. In other words, cost-effectiveness is less an inherent property of a particular test than it is a property of the decision-making algorithm in which that test is employed. [45]

\section{Limitations}

The primary limitation of our analysis was our set of clinical assumptions. These results should not be considered to have validity outside of those assumptions. This includes both the assumed practice pattern (Figure 1) and the numbers (costs and probabilities). In clinical 
settings that do not fit these assumptions our results may not apply. Another limitation is that we did not present our results in terms of quality-adjusted life years (QALYs), partly because we did not find any widely used figures for quality-of-life measurements for patients with dyspepsia, and partly because the existing literature on cost-effectiveness of $\mathrm{H}$. pylori diagnostic tests does not appear to rely heavily on QALY analysis. Also, as stated above, our model was based entirely on dyspepsia relief and did not consider more serious illnesses such as a perforated ulcer, gastric cancer, etc.

Finally, our analysis relied heavily on the findings of a Cochrane systematic review [18] in which $H$. pylori eradication was found to have only a very small clinical benefit for the average patient with nonulcer dyspepsia. Our findings may thus not apply to patient subsets for which eradication therapy could be shown to have a larger average benefit.

\section{Conclusions}

In this model of $H$. pylori diagnosis and treatment, the choice of initial noninvasive test did not have a significant impact on cost or quality outcome. This is likely attributable to the assumption of a high resource intensity practice environment. In practice settings where endoscopy is less available and/or less readily employed, these findings may not apply.

\section{Author details}

'ARUP Laboratories, Salt Lake City, Utah, USA. Department of Medicine, University of Utah, Salt Lake City, Utah, USA. ${ }^{3}$ Department of Pathology, University of Utah, Salt Lake City, Utah, USA, ARUP Laboratories, Salt Lake City, Utah, USA.

\section{Authors' contributions}

$\mathrm{KPH}$ constructed and debugged the cost-effectiveness model, performed the literature review, and drafted the initial manuscript with figures and tables. JCF provided clinical expertise and assisted in interpreting the findings. BRJ conceived the study and provided oversight and editorial review. All authors have read and approved the final version of the manuscript. Financial support: Salary support for Kyland Holmes and Brian Jackson provided by ARUP Laboratories, a nonprofit enterprise of the University of Utah

Potential competing interests: None.

Received: 20 May 2010 Accepted: 21 December 2010

Published: 21 December 2010

\section{References}

1. Talley NJ, Vakil NB, Moayyedi P: American gastroenterological association technical review on the evaluation of dyspepsia. Gastroenterology 2005, 129(5):1756-80.

2. Talley NJ: American Gastroenterological Association medical position statement: evaluation of dyspepsia. Gastroenterology 2005, 129(5):1753-5.

3. Chey WD, Wong BC: American College of Gastroenterology guideline on the management of Helicobacter pylori infection. Am J Gastroenterol 2007, 102(8):1808-25.

4. Adamsson I, Nord CE, Lundquist P, Sjostedt S, Edlund C: Comparative effects of omeprazole, amoxycillin plus metronidazole versus omeprazole, clarithromycin plus metronidazole on the oral, gastric and intestinal microflora in Helicobacter pylori-infected patients. J Antimicrob Chemother 1999, 44(5):629-40.

5. Adamsson I, Edlund C, Nord CE: Impact of treatment of Helicobacter pylori on the normal gastrointestinal microflora. Clin Microbiol Infect 2000, 6(4):175-7.

6. Calvet X, Gene E, Lopez T, Gisbert JP: What is the optimal length of proton pump inhibitor-based triple therapies for H. pylori? A costeffectiveness analysis. Aliment Pharmacol Ther 2001, 15(7):1067-76.

7. Childs S, Roberts A, Meineche-Schmidt V, de WN, Rubin G: The management of Helicobacter pylori infection in primary care: a systematic review of the literature. Fam Pract 2000, 17(Suppl 2):S6-11.

8. Choi J, Jang JY, Kim JS, Park HY, Choe YH, Kim KM: Efficacy of two triple eradication regimens in children with Helicobacter pylori infection. J Korean Med Sci 2006, 21(6):1037-40.

9. Cutler AF, Vakil N: Evolving therapy for Helicobacter pylori infection: efficacy and economic impact in the treatment of patients with duodenal ulcer disease. Am J Manag Care 1997, 3(10):1528-34.

10. Duggan AE, Tolley K, Hawkey CJ, Logan RF: Varying efficacy of Helicobacter pylori eradication regimens: cost effectiveness study using a decision analysis model. BMJ 1998, 316(7145):1648-54.

11. Ford AC, Delaney BC, Forman D, Moayyedi P: Eradication therapy in Helicobacter pylori positive peptic ulcer disease: systematic review and economic analysis. Am J Gastroenterol 2004, 99(9):1833-55.

12. Laine L, Schoenfeld P, Fennerty MB: Therapy for Helicobacter pylori in patients with nonulcer dyspepsia. A meta-analysis of randomized, controlled trials. Ann Intern Med 2001, 134(5):361-9.

13. Malfertheiner $P$, Megraud $F$, O'Morain $C$, Hungin AP, Jones $R$, Axon A, et a: Current concepts in the management of Helicobacter pylori infectionthe Maastricht 2-2000 Consensus Report. Aliment Pharmacol Ther 2002, 16(2):167-80.

14. Malfertheiner P, Megraud F, O'Morain C, Bazzoli F, El-Omar E, Graham D, et al: Current concepts in the management of Helicobacter pylori infection: the Maastricht III Consensus Report. Gut 2007, 56(6):772-81.

15. McColl KE, Dickson A, El-Nujumi A, El-Omar E, Kelman A: Symptomatic benefit 1-3 years after $\mathrm{H}$. pylori eradication in ulcer patients: impact of gastroesophageal reflux disease. Am J Gastroenterol 2000, 95(1):101-5.

16. McColl KE: Helicobacter pylori infection and long term proton pump inhibitor therapy. Gut 2004, 53(1):5-7.

17. Moayyedi P, Soo S, Deeks J, Forman D, Mason J, Innes M, et al: Systematic review and economic evaluation of Helicobacter pylori eradication treatment for non-ulcer dyspepsia. Dyspepsia Review Group. BMJ 2000, 321(7262):659-64.

18. Moayyedi P, Deeks J, Talley NJ, Delaney B, Forman D: An update of the Cochrane systematic review of Helicobacter pylori eradication therapy in nonulcer dyspepsia: resolving the discrepancy between systematic reviews. Am J Gastroenterol 2003, 98(12):2621-6.

19. Raghunath AS, Hungin AP, Wooff D, Childs S: Systematic review: the effect of Helicobacter pylori and its eradication on gastro-oesophageal reflux disease in patients with duodenal ulcers or reflux oesophagitis. Aliment Pharmacol Ther 2004, 20(7):733-44.

20. Sonnenberg A, Pauly MP, Levenson SD, Schwartz JS: Antibiotic therapy of Helicobacter pylori infection reduces healthcare expenditures related to duodenal ulcer. Am J Manag Care 1999, 5(1):53-9.

21. Spiegel BM, Vakil NB, Ofman JJ: Dyspepsia management in primary care: a decision analysis of competing strategies. Gastroenterology 2002, 122(5):1270-85.

22. Talley NJ, Vakil N: Guidelines for the management of dyspepsia. Am J Gastroenterol 2005, 100(10):2324-37.

23. Tytgat GN: Treatment of Helicobacter pylori infection: management of patients with ulcer disease by general practitioners and gastroenterologists. Gut 1998, 43(Suppl 1):S24-S26.

24. Vakil N, Connor J: Helicobacter pylori eradication: equivalence trials and the optimal duration of therapy. Am J Gastroenterol 2005, 100(8):1702-3.

25. Vakil N, Megraud F: Eradication therapy for Helicobacter pylori. Gastroenterology 2007, 133(3):985-1001.

26. Chey WD, Fendrick AM: Noninvasive Helicobacter pylori testing for the "testand-treat" strategy: a decision analysis to assess the effect of past infection on test choice. Arch Intern Med 2001, 161(17):2129-32.

27. Demiray E, Yilmaz O, Sarkis C, Soyturk M, Simsek I: Comparison of invasive methods and two different stool antigen tests for diagnosis of $\mathrm{H}$ pylori 
infection in patients with gastric bleeding. World J Gastroenterol 2006, 12(26):4206-10.

28. Gee I, Playford RJ, Turner D, Sheldon N, Wicks AC: Cost analysis of breath test versus endoscopy for dyspepsia. Digestion 2002, 65(4):207-12.

29. Hsu PI, Lai KH, Tseng HH, Liu YC, Yen MY, Lin CK, et al: Correlation of serum immunoglobulin $\mathrm{G}$ Helicobacter pylori antibody titers with histologic and endoscopic findings in patients with dyspepsia. J Clin Gastroenterol 1997, 25(4):587-91.

30. Lehmann F, Drewe J, Terracciano L, Stuber R, Frei R, Beglinger C: Comparison of stool immunoassay with standard methods for detecting Helicobacter pylori infection. BMJ 1999, 319(7222):1409.

31. Ogata SK, Kawakami E, Patricio FR, Pedroso MZ, Santos AM: Evaluation of invasive and non-invasive methods for the diagnosis of Helicobacter pylori infection in symptomatic children and adolescents. Sao Paulo Med J 2001, 119(2):67-71.

32. Zaitoun AM: Histology compared with chemical testing for urease for rapid detection of Helicobacter pylori in gastric biopsy specimens. J Clin Pathol 1993, 46(7):684-5.

33. Andrews J, Marsden B, Brown D, Wong VS, Wood E, Kelsey M: Comparison of three stool antigen tests for Helicobacter pylori detection. J Clin Pathol 2003, 56(10):769-71.

34. Braden B, Teuber G, Dietrich CF, Caspary WF, Lembcke B: Comparison of new faecal antigen test with (13)C-urea breath test for detecting Helicobacter pylori infection and monitoring eradication treatment: prospective clinical evaluation. BMJ 2000, 320(7228):148.

35. Gisbert JP, Trapero M, Pajares JM: Evaluation of 3 different tests for the detection of stool antigens to confirm Helicobacter pylori eradication after treatment. A pilot study. Gastroenterol Hepatol 2005, 28(10):615-8.

36. Laine L, Suchower L, Johnson E, Ronca P, Neil G: Accuracy of CLOtest after Helicobacter pylori therapy. Gastrointest Endosc 1998, 47(3):250-3.

37. $L i Y H$, Guo H, Zhang PB, Zhao XY, Da SP: Clinical value of Helicobacter pylori stool antigen test, ImmunoCard STAT HpSA, for detecting $\mathrm{H}$ pylori infection. World J Gastroenterol 2004, 10(6):913-4.

38. Reilly TG, Poxon V, Sanders DS, Elliott TS, Walt RP: Comparison of serum, salivary, and rapid whole blood diagnostic tests for Helicobacter pylori and their validation against endoscopy based tests. Gut 1997, 40(4):454-8.

39. Sabbi T, De AP, Colistro F, Dall'Oglio L, di Abriola GF, Castro M: Efficacy of noninvasive tests in the diagnosis of Helicobacter pylori infection in pediatric patients. Arch Pediatr Adolesc Med 2005, 159(3):238-41.

40. Shepherd AJ, Williams CL, Doherty CP, Hossack M, Preston T, McColl KE, et al: Comparison of an enzyme immunoassay for the detection of Helicobacter pylori antigens in the faeces with the urea breath test. Arch Dis Child 2000, 83(3):268-70.

41. Vaira D, Vakil N: Blood, urine, stool, breath, money, and Helicobacter pylori. Gut 2001, 48(3):287-9.

42. Vaira D, Vakil N, Menegatti M, van't HB, Ricci C, Gatta L, et al: The stool antigen test for detection of Helicobacter pylori after eradication therapy. Ann Intern Med 2002, 136(4):280-7.

43. Veijola L, Myllyluoma E, Korpela R, Rautelin H: Stool antigen tests in the diagnosis of Helicobacter pylori infection before and after eradication therapy. World I Gastroenterol 2005, 11(46):7340-4.

44. Vakil N, Rhew D, Soll A, Ofman JJ: The cost-effectiveness of diagnostic testing strategies for Helicobacter pylori. Am J Gastroenterol 2000, 95(7):1691-8.

45. Mushlin Al, Ruchlin HS, Callahan MA: Costeffectiveness of diagnostic tests. Lancet 2001, 358(9290):1353-5.

46. Raghunath A, Hungin AP, Wooff D, Childs S: Prevalence of Helicobacter pylori in patients with gastro-oesophageal reflux disease: systematic review. BMJ 2003, 326(7392):737.

47. Crabtree JE, Shallcross TM, Heatley RV, Wyatt Jl: Evaluation of a commercial ELISA for serodiagnosis of Helicobacter pylori infection. J Clin Pathol 1991, 44(4):326-8.

48. Duggan A, Logan R: Validation of a rapid whole blood test for diagnosing Helicobacter pylori infection. Conflicting results from the Helisal test. BMJ 1997, 314(7095):1688-9.

49. Karvar S, Karch H, Frosch M, Burghardt W, Gross U: Use of serum-specific immunoglobulins $A$ and $\mathrm{G}$ for detection of Helicobacter pylori infection in patients with chronic gastritis by immunoblot analysis. J Clin Microbiol 1997, 35(12):3058-61.
50. Talley NJ, Newell DG, Ormand JE, Carpenter HA, Wilson WR, Zinsmeister AR, et al: Serodiagnosis of Helicobacter pylori: comparison of enzyme-linked immunosorbent assays. J Clin Microbiol 1991, 29(8):1635-9.

51. van Der EA, van Der Hulst RW, Roorda P, Tytgat GN, Dankert J: Evaluation of three commercial serological tests with different methodologies to assess Helicobacter pylori infection. J Clin Microbiol 1999, 37(12):4150-2.

52. Erzin Y, Altun S, Dobrucali A, Aslan M, Erdamar S, Dirican A, et al: Evaluation of two enzyme immunoassays for detecting Helicobacter pylori in stool specimens of dyspeptic patients after eradication therapy. J Med Microbiol 2005, 54(Pt 9):863-6.

53. Gisbert JP, Pajares JM: Diagnosis of Helicobacter pylori infection by stool antigen determination: a systematic review. Am J Gastroenterol 2001, 96(10):2829-38.

54. Gisbert JP, Pajares JM: Stool antigen test for the diagnosis of Helicobacter pylori infection: a systematic review. Helicobacter 2004, 9(4):347-68.

55. Gisbert JP, de la MF, Abraira V: Accuracy of monoclonal stool antigen test for the diagnosis of $\mathrm{H}$. pylori infection: a systematic review and metaanalysis. Am J Gastroenterol 2006, 101(8):1921-30.

56. Syam AF, Rani AA, Abdullah M, Manan C, Makmun D, Simadibrata M, et al: Accuracy of Helicobacter pylori stool antigen for the detection of Helicobacter pylori infection in dyspeptic patients. World I Gastroenterol 2005, 11(3):386-8.

57. Moayyedi P, Soo S, Deeks J, Delaney B, Harris A, Innes M, et al: Eradication of Helicobacter pylori for non-ulcer dyspepsia. Cochrane Database Syst Rev 2006, , 2: CD002096.

Pre-publication history

The pre-publication history for this paper can be accessed here: http://www.biomedcentral.com/1472-6963/10/344/prepub

doi:10.1186/1472-6963-10-344

Cite this article as: Holmes et al.: Cost-effectiveness of six strategies for Helicobacter pylori diagnosis and management in uninvestigated dyspepsia assuming a high resource intensity practice pattern. BMC Health Services Research 2010 10:344.

\section{Submit your next manuscript to BioMed Central and take full advantage of:}

- Convenient online submission

- Thorough peer review

- No space constraints or color figure charges

- Immediate publication on acceptance

- Inclusion in PubMed, CAS, Scopus and Google Scholar

- Research which is freely available for redistribution

Submit your manuscript at www.biomedcentral.com/submit
Ciomed Central 